\title{
EL GRADO EN EDUCACIÓN SOCIAL EN LA \\ CONSTRUCCIÓN DEL ESPACIO EUROPEO DE EDUCACIÓN SUPERIOR
}

\author{
(THE DEGREE IN SOCIAL EDUCATION IN THE CREATION OF THE EUROPEAN \\ HIGHER EDUCATION AREA, EHEA)
}

José Antonio Caride Gómez

Universidad de Santiago de Compostela

\section{RESUMEN}

La creación del Espacio Europeo de Educación Superior (EEES) supone para las Universidades europeas un profundo cambio en la estructura de las enseñanzas y en su organización, pero también en la concepción del currículum y del aprendizaje de los estudiantes.

El artículo se inicia con unas reflexiones sobre los retos que traerá consigo dicho proceso, que comenzó a finales de los años noventa con las Declaraciones de La Soborna (1998) y Bolonia (1999). Prosigue con un análisis de la situación de las Universidades españolas en la Convergencia, que tiene en el año 2010 uno de sus principales horizontes.

En este contexto, el artículo analiza el estado de cuestión actual de la Educación Social en España, desde el punto de vista formativo y profesional, considerando las necesidades, competencias y contenidos que han tenerse en cuenta a la hora de diseñar el currículo del nuevo Grado en Educación Social.

\section{ABSTRACT}

The creation of the European Higher Education Area implies a deep change in, both, the studies structure and organisation of the European Universities, and also a modification in the conception of the curriculum and learning process of the students.

The article provides some reflections on the challenges posed by the process of the creation of the European Higher Education Area, that was started in the nineties with the Sorbonne Joint Declaration (1998) and the Bologne Joint Declaration (1999). An analysis 
is provided on the current situation of the Spanish Universities in the process of creation of the EHEA, which has one of its main milestones in the year 2010.

In this context, the articles analyses the current condition of the discipline of Social Education in Spain. It does so both from the formative and professional perspective, and assessing, respectively, the needs, competences and contents which must be taken on account in the process of curriculum design of the new degree in Social Education.

\section{INTRODUCCIÓN}

La necesidad de mejorar cuantitativa y cualitativamente la ordenación general del sistema educativo y, en su interior, de cada uno de los niveles que lo conforman, hace años que parecen responder a un principio básico: fomentar el aprendizaje a lo largo de toda la vida, proporcionando a los jóvenes una educación completa, que abarque los conocimientos, los valores y las competencias fundamentales que se precisan para afrontar la exigencias de una Europa más armónica e integrada. Y, consecuentemente, más comprometida con las prácticas de una ciudadanía democrática, de la vida en común y de la cohesión social, garante de oportunidades en el estudio y en el trabajo, así como en la transición -cada vez menos unidireccional- que ha de producirse entre ambos.

Así se reconoce y declara explícitamente en la Ley Orgánica 2/2006, de 3 de mayo, de Educación (BOE del 4 de mayo de 2006), en cuyo texto, conforme a los principios rectores que la inspiran, se concibe la educación "como un aprendizaje permanente", en el que "todos los ciudadanos deben tener la posibilidad de formarse dentro y fuera del sistema educativo, con el fin de adquirir, actualizar, completar y ampliar sus capacidades, conocimientos, habilidades, aptitudes y competencias para su desarrollo personal y profesional". Una meta a la que debe contribuir la propia estructura del sistema educativo, desde la Educación Infantil hasta la Universidad, pasando por la Educación Primaria, Secundaria Obligatoria, el Bachillerato, la Formación Profesional, las enseñanzas especializadas (de idiomas, artísticas, deportivas) y la Educación de Personas Adultas.

Específicamente, el capítulo II de la Ley, en su artículo 3 (las enseñanzas), se señala que el sistema educativo se organiza en etapas, ciclos, grados, cursos y niveles enseñanza de forma que asegure la transición entre los mismos y, en su caso, dentro de cada uno de ellos. En las breves indicaciones que resumen sus respectivos significados y el alcance de la formación que dispensan, se recuerda que "la enseñanza universitaria se regula por sus normas específicas". De este modo se pone énfasis en las características diferenciales de sus instituciones y de las misiones que les corresponde asumir en una sociedad que ha incrementado notablemente la circularidad de la información y del conocimiento.

Será la Ley Orgánica 4/2007, de 12 de abril, por la que se modifica la Ley 
Orgánica 6/2001, de 21 de diciembre, de Universidades (BOE 13 de abril de 2007), la que con el más alto rango normativo-legislativo regule la estructura y organización de las enseñanzas universitarias, declarando su apuesta decidida por "la armonización de los sistemas educativos superiores en el marco del espacio europeo de educación superior", asumiendo a tal fin la necesidad de una profunda reforma, basada en tres ciclos: Grado, Máster y Doctorado.

El Título XIII de la Ley se refiere expresamente al Espacio Europeo de la Enseñanza Superior, señalando al respecto que "en el ámbito de sus respectivas competencias el Gobierno, las Comunidades Autónomas y las Universidades adoptarán las medidas necesarias para completar la plena integración del sistema educativo español en el espacio europeo de enseñanza superior", anticipando en sus artículos 88,89 y 89 bis que se deberán adoptar medidas orientadas a la movilidad de estudiantes, profesores y personal de administración y servicios. Así como al impulso de la realización de programas dirigidos a la renovación metodológica de la enseñanza universitaria para el cumplimiento de los objetivos de calidad del EEES. Un propósito con el que se trata de hacer "convergente" el quehacer de nuestras Universidades con los retos que afrontan el conjunto de las Universidades europeas, con un potencial académico y humano soportado por cerca de 4.000 instituciones, en las que conviven más de 17 millones de estudiantes y en torno a un millón y medio de profesores e investigadores, que a pesar de compartir valores y tareas comunes revelan la gran heterogeneidad existente en sus estructuras y en las actuaciones que promueven.

La Educación Social, tanto en sus perfiles académicos como en las prácticas profesionales que promueve, es una muestra visible de esta pluralidad, así como de las posibilidades y limitaciones que el Espacio Europeo de Educación Superior ofrece a la hora de establecer un perfil formativo "convergente" en sus concepciones y realizaciones, a las que no es ajena la búsqueda de una mayor homologación de sus competencias profesionales en la Europa del siglo XXI.

\section{LA CONVERGENCIA EN EL ESPACIO EUROPEO DE LA EDUCACIÓN SUPERIOR Y DEL APRENDIZAJE PERMANENTE}

Las circunstancias que hemos descrito, más allá de la puesta en valor de una diversidad estimable, obligan a conciliar las bondades de la autonomía universitaria con los desafíos que supone trabajar a favor de una auténtica dimensión europea de la educación superior, garantizando que disponga de recursos suficientes y duraderos al objeto de favorecer dinámicas formativas e investigadoras congruentes con las necesidades y demandas de una sociedad en continua transformación, máxime cuando muchas de ellas apelan directamente a una mayor y mejor correspondencia entre los aprendizajes que se promueven, el desempeño profesional y la inserción en el mundo laboral. Como sabe, de un modo u otro, son procesos que han situado a la educación, en general, y a la Educación Social en particular, en un banco de pruebas especialmente sensible 
a los avatares de los acontecimientos políticos, culturales, demográficos, etc. que agitan nuestras sociedades, incidiendo decisivamente en la institucionalización académica sus saberes y en la profesionalización de sus respectivas prácticas “educativas” y/o "sociales" (Sáez Carreras y García Molina, 2006).

Es en este contexto en el que, a partir de los últimos años de la década de los noventa, Europa abriría un amplio debate acerca de la educación y la formación, del que acabará siendo un referente principal la elaboración del Libro Blanco sobre la Educación y la Formación "Enseñar a Aprender: hacia la sociedad del conocimiento", que la Comisión Europea dará a conocer en el año 1996. Un documento que tiene su proyección en numerosos debates e informes nacionales, entre los que sobresale el Informe Dearing en el Reino Unido (1997), el Informe Atali en Francia (1998), o el Informe Bricall (2000) en España. En síntesis, tal y como ha llegado a expresarse en distintos documentos oficiales de la Comisión y del Consejo Europeo -fundamentalmente a modo de recomendaciones, comunicaciones o directrices- siendo textos que insisten en la importancia de reforzar el papel de las Universidades en tres de los vértices más relevantes del conocimiento: la educación, la investigación y la innovación. Para lo cual, llega a afirmarse, es preciso invertir más y mejor en la modernización de las Universidades, asumiendo que con ello se invierte directamente en el futuro de Europa y de sus ciudadanos.

En el plano político, es así como esa pretendida Europa del conocimiento -que es o debe ser una Europa comprometida con los derechos cívicos y los valores que los amparan- imaginó el deber ser de sus Universidades, implicando a los países de la Unión en un proceso de cambio, cuya naturaleza y previsibles consecuencias están todavía lejos de poder ser apreciados en todas y cada una de sus dimensiones, por mucho que la escenografía puesta en juego ayude a visualizar algunas de sus principales identidades, comenzando por la que nombra y supuestamente define lo que hemos dado en llamar "Espacio Europeo de Educación Superior" (EEES). Para muchos, un punto de llegada con fechas más o menos precisas en sus logros u objetivos, para otros -entre los que me encuentro- un punto de partida cargado de imprecisiones y no pocas imprevisiones, resistencias y/o escepticismos.

Sea cual sea su estado actual, no debe obviarse que la construcción del EEES recibiría un impulso decisivo con la conocida como Declaración de Bolonia, firmada el 19 de junio de 1999 por los Ministros con competencias en Educación o Enseñanzas Superiores de 29 países europeos, que desde entonces será habitualmente denominado Proceso de Bolonia, aunque deba ser reconocida en su trayectoria la importancia que en sus inicios tuvo al Declaración de la Sorbona de 1998, orientada a la armonización de la arquitectura del sistema de Enseñanza Superior Europea, con la presencia de representantes de Francia, Reino Unido, Alemania e Italia.

Desde 1999, cada dos años, se celebra una Cumbre Ministerial que reali- 
za un balance de los progresos realizados y establece los objetivos para la Cumbre siguiente. Tras la Cumbre Ministerial de Bolonia (1999) se celebraron las de Praga (2001), Berlín (2003), Bergen (2005) y Londres (2007), estando previsto celebrar la próxima en Lovaina en 2009. Los trabajos de seguimiento y la preparación de los encuentros los lleva a cabo el Grupo de Seguimiento de Bolonia (BFUG) constituido en la actualidad por 46 países miembros del Proceso de Bolonia, la Comisión Europea y otras organizaciones. La "línea del tiempo" del Proceso de Bolonia, que figura en el Documento elaborado por el DirectorateGeneral for Education and Culture de la Comisión Europea Focus on the Structure of Higher Education in Europe 2006/07. National Trends in the Bologna Process (EURYDICE, 2007), refleja con claridad estos acontecimientos, así como los principios o elementos clave en los que ha puesto el acento cada uno de ellos.

La Declaración de Bolonia, a la que muchos consideran esencialmente como una iniciativa política, mediante la que se enuncian una serie de objetivos y unos instrumentos para lograrlos, aunque sin fijar unos requisitos jurídicamente exigibles, para otros se resume en el inicio de un proceso de carácter intergubernamental con participación de Universidades, estudiantes, la Comisión Europea y otras entidades. Un proceso en el que se insiste en que no se trata de homogeneizar los sistemas de Educación Superior sino de aumentar su compatibilidad y comparabilidad, respetando su diversidad. De ahí el interés en presentarlo como un espacio abierto, en el que se eliminen los obstáculos a la movilidad de estudiantes, titulados, profesores y personal de administración, que se articula en torno al reconocimiento de titulaciones y otras cualificaciones de Educación Superior, y que se apoya en la transparencia, gracias a un sistema de titulaciones organizado en tres ciclos y a la cooperación europea en la garantía de la calidad. No resulta extraño que muchas voces y textos aludan a Bolonia como un "espíritu" que alienta la renovación de los saberes y de la formación de los estudiantes, acomodando su cualificación -en el vocabulario al uso su "competencia"- a las dinámicas del mercado laboral, de manera que aumente la tasa de empleo de los titulados y se ofrezca un amplio apoyo a la transferencia y aplicabilidad de los conocimientos; o lo que viene a ser lo mismo, que estimule el crecimiento económico, la cohesión social y la mejora de la cantidad y la calidad del empleo. Con todas sus virtudes, pero también con todos sus riesgos.

La "convergencia" entre los sistemas nacionales de Educación Superior, procurando que como muy tarde en el año 2010 se alcance un desarrollo armonizado de las ofertas formativas de los distintos países que integran la Unión Europea, constituye el eje vertebrador de su puesta en práctica, asumiendo -entre otras- la necesidad de emprender acciones conjuntas, destinadas a alcanzar seis objetivos principales, en los que la Educación Social, hemos de decirlo, tiene importantes pretextos para activar su protagonismo, tanto desde el punto de vista académico como profesional; y que, básicamente se resumen en: 
- Garantizar el acceso universal y continuo de las personas al aprendizaje, con el propósito de obtener y renovar las cualificaciones requeridas para participar de forma sostenida en la sociedad del conocimiento;

- Aumentar visiblemente la inversión en recursos humanos, para dar prioridad a los ciudadanos, a los que se considera el capital más importante de Europa;

- Desarrollar métodos innovadores y contextos eficaces de enseñanza y aprendizaje para alcanzar una formación continua a lo largo y ancho de la vida;

- Mejorar significativamente las formas en que se entienden y se valoran la participación en el aprendizaje y sus resultados, sobre todo en lo que atañe al aprendizaje no formal e informal;

- Lograr que todos los ciudadanos de Europa, a lo largo de toda su vida, puedan acceder fácilmente a una información y un asesoramiento de calidad acerca de las oportunidades del aprendizaje;

- Ofrecer oportunidades de aprendizaje permanente tan cerca de los interesados como sea posible, en sus propias comunidades y, cuando proceda, con el apoyo de las tecnologías de la comunicación.

Estos objetivos se han proyectado en una serie de actuaciones prioritarias, con las que se pretende crear un sistema de grados académicos fácilmente comprensibles y comparables, fomentar la movilidad de los estudiantes, docentes e investigadores, garantizar la calidad educativa y tener en cuenta la dimensión europea de la enseñanza superior. Pero también, desbordando este logro, la articulación de un espacio europeo del aprendizaje permanente, en el que la Educación Social no sólo está llamada a ser un ámbito de estudio o de profesionalización, sino también -y muy especialmente- un agente, actor o actriz clave en sus concepciones y desarrollos, en sus planteamientos y en las iniciativas que permitan construir sus realidades. Claro está, con la concurrencia de otros agentes formativos y profesionales, con los que comparte o debiera compartir un mismo afán socializador y mediador. Entender los estudios en Educación y la formación de sus profesionales (como maestros, profesores, educadores, pedagogos, psicopedagogos, etc.) como arte y parte de un proceso que aspira a una nueva concepción pedagógica de las enseñanzas y de los aprendizajes se convierte, de este modo, en un acto de congruencia... al que ninguna práctica educativa puede mostrarse indiferente, ya sea en el sistema educativo-escolar o en cualquiera de los escenarios que habilita la sociedad para las mal llamadas educación no formal e informal; y que para nosotros -con todos los matices que la expresión requiera- insistimos en nombrar como Educación Social.

En este sentido, debe advertirse que pocos títulos académicos tienen la necesidad de dar una respuesta tan coherente y, al tiempo, socialmente valiosa, 
como aquellas que tienen como objeto y sujeto de sus contenidos formativos a la propia sociedad. $\mathrm{O}$, si se desea expresar con mayor concreción, a aquellos estudiantes universitarios que optan por vincular su preparación académica y su desempeño profesional a tareas, compromisos y responsabilidades en la sociedad, para la sociedad y -muy a menudo- con la sociedad, allí donde los problemas y dificultades que aquella presenta obligan a hacer conciliable la competencia técnica con las obligaciones éticas, el saber hacer con el saber ser.

\section{DEL ESPÍRITU DE BOLONIA A LA REFORMA DE LAS UNIVERSIDADES EN EL CONTEXTO UNIVERSITARIO ESPAÑOL}

El sentimiento de pertenecer a una gran colectividad, de compartir un trayecto común y al tiempo diferente, no puede en ningún caso crearse o construirse artificialmente. Así lo expresaba Pascal Fontaine (2003), antiguo colaborador de Jean Monnet y profesor del Instituto de Estudios Políticos de París, al reivindicar nuevas perspectivas de desarrollo para el conocimiento, la formación y la investigación en la vida cotidiana de los ciudadanos; y, por tanto, de todas aquellas entidades, colectivos e instituciones que estén en condiciones de contribuir a esta tarea en cada país asumiendo los compromisos y responsabilidades que ello comporta.

En la Educación Superior y en las Universidades este argumento se ha trasladado, no sin resistencias, a decisiones y propuestas animadas un afán transformador en el que se reconocen unas líneas básicas de actuación a observar en cada país y en el contexto europeo, de las que se esperan repercusiones positivas en aspectos que buscan dar prioridad al aprendizaje, al aprender a aprender, a la promoción de planes centrados en el alumno, a la formación integral, la realización de actividades diversas y complementarias, al trabajo en equipo, etc. En todo caso, de poder hacerlo sin demoras, acompasando la participación activa de los diferentes interlocutores que se dan cita en el proyecto con una agenda cuyos itinerarios deberían permitir que el 2010 llegara a todos los países a la vez. En el caso español, cabe recordar que en marzo de 2007, un documento elaborado por el Ministerio de Educación y Ciencia con el título Implantación del nuevo Sistema Educativo, preveía que el calendario de aplicación de las titulaciones adaptadas al EEES permitirá que en el curso 2008-09 comiencen la impartición de los nuevos Grados y que en julio de 2012 concluyan su formación los primeros graduados y graduadas.

En opinión de Michavila y Zamorano la creación de un nuevo Espacio Europeo de la Educación Superior supone para las Universidades europeas un profundo cambio en la estructura de las enseñanzas y en su organización, pero también en el paradigma educativo, lo que en el caso español ha de traducirse en una clara "voluntad de avanzar hacia el horizonte descrito por las declaraciones que definen los principios del futuro EEES, a la par que asienten la necesidad de llevar a cabo reformas profundas en los planes de estudio y en los programas de las asignaturas para su cometido" $(2007,34)$. 
Considerando el Ministerio de Educación y Ciencia español que la Ley Orgánica 4/2007, de 12 de abril, por lo que se modificó la Ley Orgánica 6/2001, de 21 de diciembre, de Universidades, "sienta las bases precisas para realizar una profunda modernización de la Universidad española, en el BOE del 30 de octubre de 2007, fue promulgado el Real Decreto 1393/2007, de 29 de octubre, por el que se establece la ordenación de las enseñanzas universitarias oficiales, al objeto de subrayar cuáles serán los principios y directrices básicas que articularán las enseñanzas y los títulos que se hayan de impartir y expedir, profundizando a tal fin "en la concepción y expresión de la autonomía universitaria de modo que en lo sucesivo serán las propias universidades las que crearán y propondrán, de acuerdo con las reglas establecidas" tales enseñanzas y titulaciones.

El Real Decreto dispone medidas que además de buscar la compatibilidad con el EEES, "flexibilizan la organización de las enseñanzas universitarias, promoviendo la diversificación curricular y permitiendo que las universidades aprovechen su capacidad de innovación, sus fortalezas y oportunidades". Al respecto y con vistas a los objetivos que deben ser alcanzados, estima que "en el diseño de un título deben reflejarse más elementos que la mera descripción de los contenidos formativos, ya que al concebir el plan de estudios como un proyecto de implantación de una enseñanza universitaria, deben figurar otros elementos, como son: justificación, objetivos, admisión de estudiantes, contenidos, planificación, recursos, resultados previstos y sistema de garantía de calidad".

Más aún, "los planes de estudios conducentes a la obtención de un título deberán, por tanto, tener en el centro de sus objetivos la adquisición de competencias por parte de los estudiantes, ampliando, sin excluir, el tradicional enfoque basado en contenidos y horas lectivas. Se debe hacer énfasis en los métodos de aprendizaje de dichas competencias así como en los procedimientos para evaluar su adquisición. Se proponen los créditos europeos, ECTS, tal y como se definen en el Real Decreto 1125/2003, de 5 de septiembre, como unidad de medida que refleja los resultados del aprendizaje para alcanzar los objetivos establecidos en el plan de estudios, poniendo en valor la motivación y el esfuerzo del estudiante para aprender". La empleabilidad de los titulados, la posesión de competencias y conocimientos adecuados para el ejercicio profesional, la movilidad de los estudiantes, o la formación en los valores democráticos y en los Derechos Humanos... añaden a aquél propósito el deseo de no olvidar "que el actor principal en viaje es el estudiante" (Michavila y Zamorano, 2007, 58).

Los planes de estudio elaborados habrán de ser verificados por el Consejo de Universidades y autorizados en su implantación por la correspondiente Comunidad Autónoma, de acuerdo con lo establecido en la Ley de Universidades. Se entiende, en esta perspectiva, que el proceso deberá propiciar la articulación de una combinación adecuada de capacidades y competencias, a partir de programas universitarios diseñados y planteados de forma que los futuros titulados y tituladas alcancen una formación sólida y completa. Por lo que la oferta de titulaciones y de programas formativos ha de ser decididamente innovado- 
ra, de modo tal que a las capacidades disciplinares se sumen otras de carácter más amplio relacionadas con las demandas del mercado laboral. El Capítulo II del Real Decreto, que define y precisa cuál será la "estructura de las enseñanzas universitarias oficiales" conducentes a la obtención de títulos de carácter oficial y con validez en todo el territorio del Estado, articula las opciones formativas en tres ciclos, denominados respectivamente Grado, Máster y Doctorado.

Del Grado y de sus enseñanzas se espera la obtención, por parte de los estudiantes de una formación general, en una o varias disciplinas, orientada a la preparación para el ejercicio de actividades de carácter profesional. Las Enseñanzas de Máster pretenden la adquisición por parte del estudiante de una formación avanzada, de carácter especializado o multidisciplinar, orientada a la especialización académica o profesional, o bien a promover la iniciación en tareas investigadoras. Las Enseñanzas de Doctorado tienen como finalidad la formación avanzada del estudiante en las técnicas de investigación; y podrán incorporar cursos, seminarios u otras actividades orientadas a la formación investigadora e incluirá la elaboración y presentación de la correspondiente tesis doctoral, consistente en un trabajo original de investigación.

En las enseñanzas oficiales de Grado, los planes de estudio tendrán 240 créditos, que contendrán toda la formación teórica y práctica que el estudiante debe adquirir: aspectos básicos de la rama de conocimiento, materias obligatorias u optativas, seminarios, prácticas externas, trabajos dirigidos, trabajo de fin de Grado u otras actividades formativas. Cada Universidad propondrá la adscripción del correspondiente título de Graduado o Graduada a alguna de las siguientes ramas de conocimiento: a) Artes y Humanidades; b) Ciencias; c) Ciencias de la Salud; d) Ciencias Sociales y Jurídicas; e) Ingeniería y Arquitectura.

El Plan de Estudios de cada Grado deberá contener un mínimo de 60 créditos de formación básica, de los que al menos 36 estarán vinculados a algunas de las materias básicas por rama de conocimiento a las que se adscriba el título, que en el caso de las titulaciones de Educación será la rama de Ciencias Sociales y Jurídicas, a la que están vinculadas un total de 12 materias, que son: Antropología, Ciencia Política, Comunicación, Derecho, Educación, Empresa, Estadística, Geografía, Historia, Psicología y Sociología. Estas materias deberán concretarse en asignaturas con un mínimo de 6 créditos cada una y serán ofertadas en la primera mitad del plan de estudios. Los créditos restantes hasta 60 , en su caso, deberán estar configurados por materias básicas de la misma u otras ramas del conocimiento, o por otras materias siempre que se justifique su carácter básico para la formación inicial del estudiante o su carácter transversal. Las prácticas externas tendrán una extensión máxima de 60 créditos y deberán ofrecerse preferentemente en la segunda mitad del plan de estudios. El trabajo de fin de Grado tendrá entre 6 y 30 créditos, deberá realizarse en la fase final del plan de estudios y estar orientado a la evaluación de competencias asociadas al título. Complementariamente, los estudiantes podrán obtener recono- 
cimiento académico en créditos por la participación en actividades universitarias culturales, deportivas, de representación estudiantil, solidarias y de cooperación hasta un máximo de 6 créditos del total del plan de estudios cursado.

Los planes de estudio conducentes a la obtención del título de Máster Universitario, serán elaborados por las Universidades y verificados de acuerdo con lo establecido en el Real Decreto 1393/2007, de 29 de octubre, por el que se establece la ordenación de las enseñanzas universitarias oficiales (BOE del 30 de octubre de 2007). Tendrán una duración que oscilará entre un mínimo de 60 y un máximo de 120 créditos, que permitirán impartir toda la formación teórica y práctica que el estudiante deba adquirir: materias obligatorias, materias optativas, seminarios, prácticas externas, trabajos dirigidos, trabajo de fin de Máster, actividades de evaluación, y otras que resulten necesarias según las características propias de cada título. Estas enseñanzas concluirán con la elaboración y defensa pública de un trabajo de fin de Máster, que tendrá entre 6 y 30 créditos. Las enseñanzas de Doctorado y sus correspondientes Programas, que permitirán la obtención del título de Doctor o Doctora, contienen un período de formación y un período de investigación organizado, con unos requisitos de acceso que suponen el cumplimiento de unas determinadas condiciones académicas, que deberá culminar con la elaboración de la Tesis Doctoral, que consistirá en un trabajo original de investigación elaborado por el candidato en cualquiera de las disciplinas.

El Real Decreto incluye un primer Anexo con el modelo de memoria para la solicitud y verificación de los Títulos Oficiales. La memoria configura el proyecto de título oficial que deben presentar las Universidades para su correspondiente verificación, constituyendo el compromiso de la institución sobre las características del título y las condiciones en las que se van a desarrollar las enseñanzas.

Concluiremos indicando que el nuevo escenario que se perfila en el Real Decreto, sugiere el diseño de la nueva formación de titulaciones y especialidades en el sistema universitario español y en el de sus Comunidades Autónomas -algunas de ellas con una regulación específica de las líneas generales de implantación de los Estudios de Grado y Postrado en sus respectivos territorios- , además de perseguir el objetivo irrenunciable de la transmisión del conocimiento, aspira a dotarse de una estructura más abierta, diversa y versátil, que permita y favorezca una mejor adaptabilidad a una realidad laboral cambiante en exigencias y capacidades, que facilite y promueva la formación a lo largo de la vida que demanda la sociedad actual.

Este doble objetivo, encaminado a favorecer la movilidad y las oportunidades laborales de los titulados en el mercado laboral europeo, constituye un reto para las Universidades, que deberán ser capaces de aprovechar el proceso de armonización europea para articular una oferta congruente y en línea con las demandas sociales, subrayando cada una su perfil diferenciado y optimizan- 
do sus potencialidades. Sin duda, una opción que también requerirá que la implantación de los estudios de Grado y Postgrado partan de un análisis de las necesidades tanto materiales como de los recursos humanos que se precisan para avanzar en el proceso.

En Educación Social, al igual que en los demás Grados que se proponen para su implantación en Educación (Maestro de Educación Infantil, Maestro de Educación Primaria, Pedagogía), se ha llevado a cabo con desiguales resultados, lo que también -de partida- tendrá efectos dispares en los modos de diseñar curricularmente las propuestas, aún cuando deba reconocerse el esfuerzo realizado por la Conferencia de Decanos y Directores de Magisterio y Educación para establecer unas "orientaciones" básicas para su definición. En este sentido, fruto de algunos consensos básicos, deben valorarse los acuerdos adoptados por la Comisión Permanente de la Conferencia en una sesión celebrada en la Universidad Complutense de Madrid el pasado 6 de marzo de 2008. Aunque, inevitablemente, sus deliberaciones y los resultados de las mismas forman parte de un recorrido de más amplios horizontes temporales, institucionales y sociales.

\section{EL GRADO DE EDUCACIÓN SOCIAL COMO RENOVACIÓN Y CONSO- LIDACIÓN DE UNA FORMACIÓN UNIVERSITARIA EMERGENTE}

Buena parte de los avances señalados trascienden el quehacer de cada Universidad o, cuando menos, obligan a considerarlas en su conjunto, asumiendo la necesidad e importancia de los procesos que han posibilitado o están posibilitando una actuación concertada por parte de distintas instancias universitarias (Consejo de Coordinación Universitaria, Conferencia de Rectores, etc.). Y que, en el caso de las titulaciones de Educación, conlleva reconocer el especial protagonismo que ha tenido la Conferencia de Decanos y Directores de Magisterio y Educación en la dinamización, coordinación y toma decisiones relativa a los títulos de Maestro, Pedagogía, Psicopedagogía y Educación Social. Como también lo ha tenido, en gran medida a través del apoyo prestado por la Conferencia al proceso que posibilitó la elaboración y posterior publicación, por la ANECA, de los Libros Blancos de los títulos de Maestro y de Pedagogía y Educación Social.

Del proceso seguido en la elaboración del Libro Blanco de los Grados de Pedagogía y Educación Social ha hecho un excelente resumen el profesor Luís Lizosain (2005), recordando como en el marco de las convocatorias realizadas por la ANECA para el estudio y diseño de los planes de estudio y futuros títulos de Grado se constituiría la "Red de Educación", coordinada por el profesor Aurelio Villa, de la Universidad de Deusto. Una red a la que en un principio se sumaron 23 Universidades y 2 asociaciones profesionales, pero que a lo largo de los meses llegarían a aglutinar a un total de 39 Universidades en las que se imparten Pedagogía y/o Educación Social, que según datos de la propia Agencia representa el 95 por ciento de los centros que imparten enseñanzas en estos 
campos. Además participaron cinco Asociaciones y dos Colegios Profesionales: el Colegio Estatal de Educadores Sociales, el Colegio de Pedagogos de Cataluña, la Asociación de Educadores Sociales (ASEDES), la Asociación Española de Orientación Psicopedagógica (AEOP), la Sociedad Española de Pedagogía (SEP) y la Sociedad Iberoamericana de Pedagogía Social (SIPS).

El trabajo realizado posibilitaría, en un primer momento, el estudio comparado de la situación en Europa de las titulaciones en educación, sin considerar las orientadas a la formación de docentes (objeto del Informe de la Red de Magisterio), conformando un total de 20 países. Con la intención de sistematizar el trabajo comparativo se diseño una ficha para cada país y titulación con 11 campos: denominación oficial de los estudios, centros en los que se imparten, requisitos de admisión o acceso, duración de la titulación, perfil profesional, contenidos académicos, perfil profesional de la titulación, etc. La información fue sistematizada, definiéndose un total de once agrupaciones temáticas, a las que cabe considerar como áreas o ámbitos de formación, trabajo o intervención que desarrolla una titulación determinada o para las que prepara la misma.

Tras la puesta en común en el plenario de la Red de las conclusiones a las que se llegó en los grupos de trabajo (análisis de la perspectiva europea y española), se abordó la fase del Informe orientada a estudiar los perfiles y competencias profesionales de los pedagogos y los educadores sociales. Se tomaron en consideración las competencias transversales definidas en el proyecto para los diferentes ámbitos, procediendo a realizar una descripción de los conocimientos y competencias académico-profesionales específicas en relación con cada perfil. El resultado intermedio de este proceso -señala Lizasoaín (2005: 722)fue "una tabla basada en el modelo ANECA que sirvió para clasificar y valorar los conocimientos y las competencias definidas".

\begin{tabular}{|l|c|c|}
\hline \multicolumn{1}{|c|}{ ÁMBITOS } & $\begin{array}{c}\text { GRADO EN } \\
\text { PEDAGOGÍA }\end{array}$ & $\begin{array}{c}\text { GRADO EN } \\
\text { EDUCACION } \\
\text { SOCIAL }\end{array}$ \\
\hline 1. Administración y Gestión Educativa & $\mathrm{X}$ & \\
\hline 2. Orientación e intervención psicopedagógica & $\mathrm{X}$ & \\
\hline 3. Diseño, desarrollo y evaluación de procesos y medios educativos & $\mathrm{X}$ & \\
\hline 4. Formación y desarrollo en organizaciones & $\mathrm{X}$ & \\
\hline 5. Educación familiar y desarrollo comunitario & & $\mathrm{X}$ \\
\hline 6. Educación y mediación para la integración social & $\mathrm{X}$ \\
\hline 7. Educación del ocio, animación y gestión sociocultural & $\mathrm{X}$ \\
\hline 8. Intervención socioeducativa en la infancia y juventud & & $\mathrm{X}$ \\
\hline 9. Educación de personal adultas y mayores & $\mathrm{X}$ & $\mathrm{X}$ \\
\hline 10. Atención socioeducativa a la diversidad & $\mathrm{X}$ & $\mathrm{X}$ \\
\hline
\end{tabular}

Cuadro $\mathrm{n}^{\circ}$;

Ámbitos contemplados en la definición de los títulos de Pedagogía y Educación Social Fuente: Villa (2005).

La conclusión, prosigue Lizasoaín, sería que se definieron 10 ámbitos (véase cuadros $\mathrm{n}^{\circ} 1$ y 2 ), que reflejan la adscripción diferencial de los mismos a 
las dos titulaciones, "excepto en el caso de los dos últimos, los ámbitos son específicos de una u otra titulación". Ambas, en todo caso, están extraídas del Informe final remitido a la ANECA. En su presentación, el profesor Aurelio Villa $(2005,17)$ pondría de manifiesto que "la agrupación de las Facultades de Educación en una Red común de trabajo supuso un hito importante en el intercambio y relaciones entre las distintas Facultades, ya que ha sido la primera vez que se reunían como grupo desde su fundación. Hemos de destacar aquí el valor de consenso que se ha sabido lograr y mantener a lo largo de todo este trabajo". Su mejor exponente, como también expresa, el profesor Villa sería la aprobación por unanimidad del Informe entonces presentado.

A mediados del año 2006, la Conferencia de Decanos y Directores de Magisterio y Educación convocaría, primero en la Universitat de Barcelona (el 1 y 2 de junio) y posteriormente en la Universitat des Illes Balears (el 22 y 23 de junio, en este caso con la colaboración de la Sociedad Iberoamericana de Pedagogía Social-SIPS), dos Jornadas de debate conducentes a la elaboración de las Fichas Técnicas de propuesta de los títulos universitarios de Grado en Pedagogía (Barcelona) y Educación Social (Palma de Mallorca) según el Real Decreto 55/2005 de 21 de enero por el que se establece la estructura de las enseñanzas universitarias y se regulan los estudios universitarios oficiales de Grado.

\begin{tabular}{|c|c|c|}
\hline GRADO & ÁMBITOS & PERFILES \\
\hline \multirow{4}{*}{ 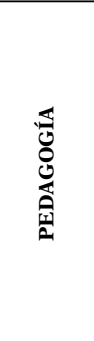 } & 1. Administración y Gestión Educativa & $\begin{array}{l}\text { 1.1. Gestor de centros educativos } \\
\text { 1.2. Inspector y supervisor de la administración educativa } \\
\text { 1.3. Evaluador de sistemas e instituciones educativas }\end{array}$ \\
\hline & 2. Orientación e intervención psicopedagógica & $\begin{array}{l}\text { 2.1. Orientador personal, académico y profesional } \\
\text { 2.2. Orientador familiar }\end{array}$ \\
\hline & $\begin{array}{l}\text { 3. Diseño, desarrollo y evaluación de procesos } \\
\text { y medios educativos }\end{array}$ & $\begin{array}{l}\text { 3.1. Diseñador y evaluador de recursos curriculares, didácticos y } \\
\text { tecnológicos } \\
\text { 3.2. Diseñador y evaluador de procesos de enseñanza- aprendizaje } \\
\text { 3.3. Formador pedagógico de la función docente }\end{array}$ \\
\hline & 4. Formación y desarrollo en organizaciones & $\begin{array}{l}\text { 4.1. Consultor y gestor de formación en las organizaciones } \\
\text { 4.2. Formador de formadores }\end{array}$ \\
\hline \multirow{4}{*}{ 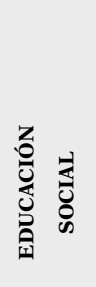 } & 5. Educación familiar y desarrollo comunitario & $\begin{array}{l}\text { 5.1. Educador de familia } \\
\text { 5.2. Agente socioeducativo de desarrollo comunitario }\end{array}$ \\
\hline & $\begin{array}{l}\text { 6. Educación y mediación para la integración } \\
\text { social }\end{array}$ & $\begin{array}{l}\text { 6.1. Educador de familia } \\
\text { 6.2. Diseñador y evaluador de procesos de integración social }\end{array}$ \\
\hline & $\begin{array}{l}\text { 7. Educación del ocio, animación y gestión } \\
\text { sociocultural }\end{array}$ & $\begin{array}{l}\text { 7.1. Educador en tiempo libre y ocio } \\
\text { 7.2. Animador sociocultural } \\
\text { 7.3. Gestor de programas y recursos socioculturales } \\
\end{array}$ \\
\hline & $\begin{array}{l}\text { 8. Intervención socioeducativa en la infancia y } \\
\text { juventud }\end{array}$ & $\begin{array}{l}\text { 8.1. Educador en instituciones de atneción e inserción social } \\
\text { 8.2. Mediador en procesos de acogida y adopción }\end{array}$ \\
\hline \multirow{2}{*}{ 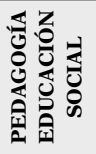 } & 9. Educación de personas adultas y mayores & $\begin{array}{l}\text { 9.1. Orientador socio-laboral } \\
\text { 9.2. Educador de personas adultas y mayores }\end{array}$ \\
\hline & 10. Atención socioeducativa a la diversidad & $\begin{array}{l}\text { 10.1. Pedagoggo especialista en atención a la diversidad educativa } \\
\text { 10.2. Dinamizador para la inserción sociolaboral }\end{array}$ \\
\hline
\end{tabular}

Cuadro $n^{\circ} 2$;

Ámbitos y perfiles profesionales asociados a los títulos de Pedagogía y Educación Social Fuente: Villa (2005). 
Más recientemente, el Grupo de Trabajo de Pedagogía y Educación Social constituido en el seno de la Conferencia de Decanos y Directores de Magisterio y Educación, aportaría las conclusiones de su trabajo a la Asamblea de la Conferencia, celebrada en Córdoba el 7 y 8 de noviembre de 2007, declarando expresamente que son "conclusiones que se realizan en torno a sendos documentos de Pedagogía y Educación Social, presentados para el debate en la Asamblea de Córdoba". Y que se resumen en:

a) Adoptar una estructura en los planes de estudio de 60 créditos comunes y su distribución en 36/24 dentro de los Grados de Educación: promocionar la diferenciación de los Títulos de Pedagogía y Educación Social y hacerlo compatible con la optimización de recursos. Para ello es recomendable buscar estructuras comunes y favorecer el reconocimiento de créditos si hay algún estudiante que quiere cambiar la titulación. Al menos el 50\% comunes en todo el área de educación. Paralelamente se recomienda asesorar a los estudiantes a que escojan como materias comunes un porcentaje amplio del ámbito de la educación. Se resalta la importancia, como horizonte ideal, que los estudiantes tengan una formación amplia e interdisciplinar como formación de base.

b) Concepción, tamaño y ubicación del Prácticum así como del Trabajo de fin de carrera-Memoria: aunque el Decreto indica que el prácticum deberá ubicarse en el tercer y cuarto año, algunas Universidades explican que buscarán fórmulas para ir incorporando el contacto con el ámbito profesional desde primer curso. Probablemente bajo un epígrafe del tipo "Análisis de problemas educativos actuales-casos prácticos", de modo que se pueda encauzar dicha cuestión más allá de los dos últimos cursos. Respecto al tamaño del prácticum se recomienda intentar incrementarlo. Combinando prácticum y trabajo de fin de carrera, puede llegar a 60 créditos. El bloque que se denomine prácticum debería ser como mínimo de 30 créditos, ajustando convenientemente los demás ámbitos. Se comenta también la importancia de no identificar reflexión y teoría como antónimo de profesionalización. El trabajo de fin de carrera debería tener una presentación pública.

c) Decisiones acerca del porcentaje de la optatividad: que no debería superar un 10 ó un 15\%. La oferta debería estar asociada a itinerarios o ámbitos concretos. Son cuestiones que ayudarán también a diferenciar las dos titulaciones.

d) Decisiones acerca de los itinerarios posibles: se considera que no pueden fijarse a priori sino en función de contextos. Se liga con la cuestión de la diferenciación entre los dos Grados, que tendrá repercusiones en los itinerarios y que ayudarán a diferenciar entre grados. El benchmarking puede ayudar a compartir visiones y a generalizar propuestas entre universidades. El contexto territorial puede favorecer el buscar ámbi- 
tos distintivos. Se valora como interesante revisar la relación de campos profesionales que han establecido los colegios profesionales (Baleares, Cataluña, Valencia, Andalucía, etc.).

Otras aportaciones aluden a la diferenciación entre los dos Grados, contextos y ámbitos; a la internacionalización de las enseñanzas en el marco europeo y a las políticas de movilidad; a la participación de los Colegios Profesionales, y al futuro de las enseñanzas de Psicopedagogía. En relación con el Grado de Educación Social pueden resumirse en tres epígrafes principales:

a) Tomar en consideración la diferencia entre los Grados de Pedagogía y Educación Social, de sus respectivos contextos y ámbitos: se resalta la importancia de recuperar los trabajos de los libros blancos y de las jornadas de Barcelona y Palma en los que se establecen ámbitos comunes y específicos. Se trata de un patrimonio común, fruto de un amplio debate, esfuerzo y consenso entre centros y que además contó con los colegios, asociaciones y sociedades vinculadas con los dos títulos.

b) Promover la internacionalización de los estudios: en este sentido, se recomienda favorecer estrategias de carácter didáctico y docente o formativo en relación a Europa. Las Universidades, se apunta, deberán hacer también apuestas estratégicas en temas de internacionalización sin descuidar ni Europa ni Latinoamérica, así como otras zonas geográficas próximas. En relación con la movilidad se recomienda favorecer políticas comunes entre las Facultades para promoverla. Por ejemplo, armonizando períodos lectivos, de prácticum y otros elementos estructurales que posibiliten sintonizar mejor los períodos en los que se haga efectiva la movilidad. Además se insiste en la importancia de incorporar otras lenguas, distintas de la propia en el currículum, tanto estatales como europeas.

c) Reconocer y activar la participación de colegios profesionales: en algunas Universidades se han configurado consejos asesores y convenios de colaboración en los que participan los colegios profesionales. La función de dichos Colegios y otras instituciones tendrá que ver, entre otras, con las aportaciones para la elaboración de títulos, especialmente tras elaborar la estructura académica y conjugarla con la profesionalización y también con los procesos de aseguramiento de la calidad y acreditación. Se recomienda que estas prácticas se extiendan a todas las Universidades.

El 1 de febrero de 2008 tuvo lugar en la Facultad de Educación de la Sede Central de la UNED una reunión a la que acudieron representantes de los Centros que están impartiendo actualmente las titulaciones de Pedagogía y/o Educación Social, o que tienen la intención de implantarlas en el futuro, con el propósito de avanzar en la concreción de los perfiles profesionales del pedago- 
go y del educador social, de las competencias asociadas a ambos Grados, de la estructura curricular básica de cada Título, de las materias formativas básicas y de las optativas, etc. tomando como soporte de los documentos generados por la Conferencia de Decanos y Directores de Centros de Magisterio y Educación. A pesar de que no se llegaron a concretar satisfactoriamente las propuestas que deberían permitir iniciar de forma coordinada el diseño de los nuevos Grados, pero aceptando la urgencia de generar orientaciones que concreten las señas de identidad de los ámbitos específicos para cada Título, la reunión avanzó cuatro criterios que deberían ser respetados como punto de partida, y que, en lo fundamental, se resumen en:

- Ningún título supere la redacción de veinte competencias.

- Introducir más competencias que las que se mencionan al principio, "relacionadas con el ámbito de los conocimientos, comprensión, etc. al entender que posteriormente en los objetivos formativos de las diferentes materias/asignaturas se abordarán estos ámbitos", para lo que se supone "que si alguien dispone de una determinada competencia (destreza o habilidad), es que ya cuenta con los conocimientos que la sustentan".

- Examinar detalladamente "las posibles nuevas propuestas de aumento de las competencias, por si pudiera descubrirse que ya están subsumidas por otra de orden superior".

- Finalmente, "procurar que cada Título mantenga su identidad sin interferencias notables con el otro".

Cabe señalar que las propuestas realizadas coincidieron en agrupar las competencias en siete grandes bloques, con las siguientes denominaciones:

1. Conocimiento, comprensión y análisis crítico.

2. Programación, planificación, anticipación de la acción.

3. Acción educativa o socioeducativa, trabajo directo con las personas.

4. Evaluación.

5. Coordinación, gestión y organización.

6. Asesoramiento, orientación y acompañamiento.

7. Mejora permanente de la profesión, investigación sobre la propia práctica, intercambio profesional.

Con ambas referencias, en los primeros días del mes de marzo de 2008, la Comisión Permanente de la Conferencia de Decanos y Directores de Magisterio y Educación debatiría las propuestas que les fueron trasladadas, adoptando y 
difundiendo distintos acuerdos acerca de los perfiles profesionales de los dos Grados, de las competencias específicas de cada uno de ellos, de la estructura de los Grados y de las propuestas de materias formativas comunes para ambos Títulos. Centrándonos en los últimos apartados, lo más destacable incidirá en:

a) Considerar que los 60 ECTS (European Credit Transfer System) de Formación Básica sean comunes a las dos titulaciones, e incluso comunes, al menos parcialmente, también con Magisterio. De ahí que se propongan las mismas materias para los dos Grados, con el siguiente reparto: 36 ECTS (6 asignaturas) propias de la materia de "Educación; 24 ECTS (4 asignaturas) bien de materias de la Rama de Sociales y Jurídicas o de otras ramas (Psicología, Sociología, Filosofía, Derecho, Economía, Estadística, Política, Idiomas, etc.).

b) Organizar las materias o asignaturas en unidades de 6 ECTS, semestrales.

c) Sugerir una arquitectura de los Grados que contemple una estructuración de la formación y del conjunto de los procesos de enseñanzaaprendizaje que adopte el siguiente esquema: 60 ECTS de formación básica, ya aludida; un mínimo de 102 y un máximo de 126 ECTS de formación específica del Grado; entre 24 y 30 ECTS de materias optativas; un mínimo de 30 y un máximo de 42 ECTS de prácticum (prácticas reales, preparación de las mismas, orientaciones, seminarios, memoria, etc.); y, por último, un mínimo de 6 y un máximo de 12 ECTS asignados a un Trabajo Final.

A diferencia de lo sugerido en la Ficha Técnica de Propuesta de título de Grado, según el Real Decreto 55/2005, de 21 de enero, para las enseñanzas universitarias en Educación Social, redactada a partir de las Jornadas de Estudio y Debate sobre el Título de Grado en Educación Social, celebradas en Palma de Mallorca en junio de 2006, por iniciativa de la Conferencia de Decanos y Directores de Magisterio y Educación, con la colaboración de la Sociedad Iberoamericana de Pedagogía Social (SIPS), el nuevo esquema que anticipan estos acuerdos adoptaría la estructura que se presenta a continuación (gráfica $\mathrm{n}^{\circ} 1$ ): 


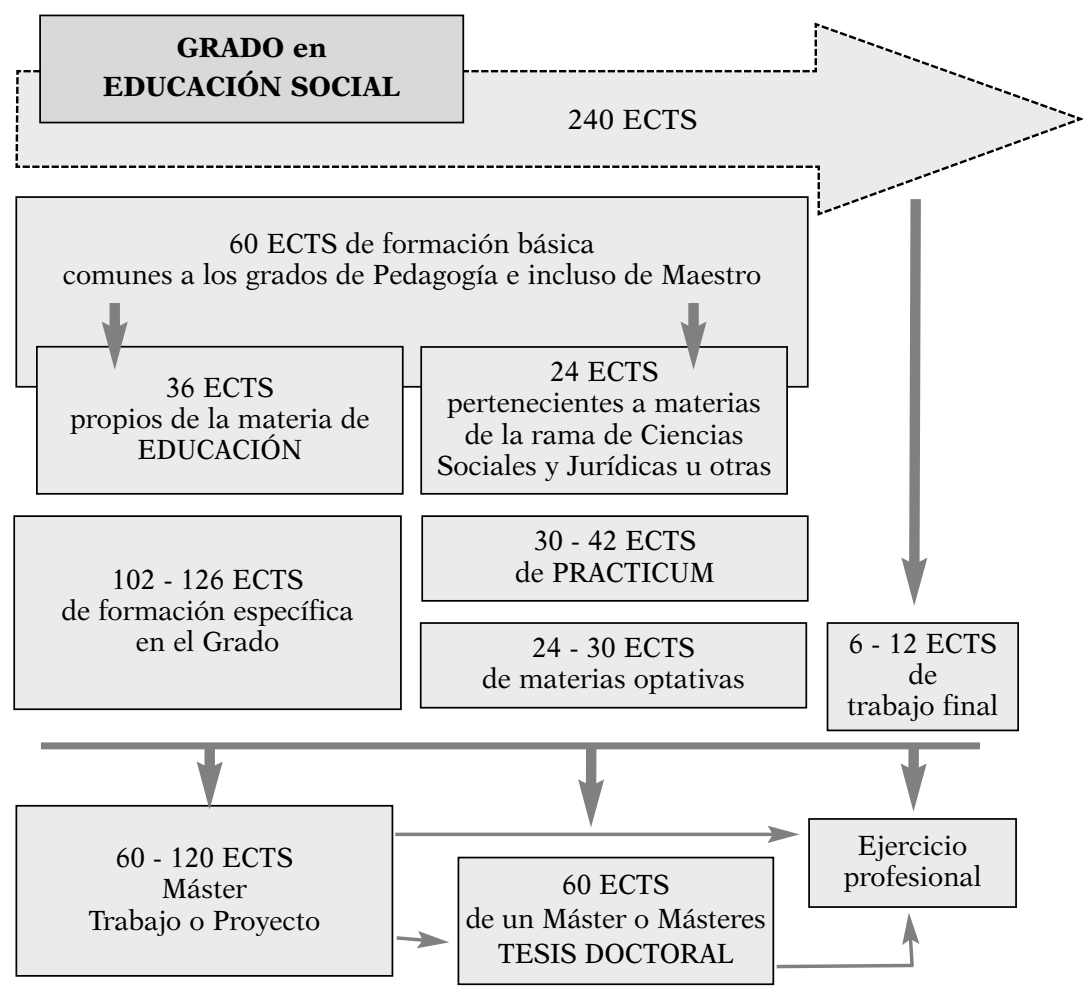

Gráfica ${ }^{\circ}$ 1; Estructura de la propuesta académica de Grado en Educación Social Elaboración propia.

Aunque las urgencias del presente pasen por alto muchas de las circunstancias que han posibilitado la implantación y desarrollo de una formación académica universitaria en Educación Social en nuestro país, con Planes de Estudios vigentes en un total de 36 instituciones universitarias y con más de 20.000 estudiantes cursando sus enseñanzas (curso académico 2006-07), necesariamente cualquier lectura prospectiva acerca de su perfil formativo y profesional debe remitirse a un pasado en el que, hace poco más de dos décadas, en uno de los Informes Técnicos del Grupo 15 -constituido a instancias del Pleno del Consejo de Universidades para elaborar las directrices propias de los Títulos en Educación- propusiera la creación de una Diplomatura en Educación Social, justificando tal propuesta en "necesidades sociales de diverso tipo, el que la educación y la formación actúen a través de nuevos canales y medios, las necesidades de la educación relacionadas con el mundo del ocio, así como el reconocimiento de que la formación es una necesidad durante toda la vida activa de los sujetos, e incluso fuera de ella, han planteado la necesidad de considerar el ámbito de la educación no formal y fuera de las instituciones escolares como un campo en el que existe una demanda social de personal específicamente formado para ellas que en la actualidad no atiende la oferta actual de títulos universitarios". 
Al margen de otras consideraciones, entre las que cabría mencionar el hecho de que también se sugirió la creación de una Licenciatura en Educación Social, el debate suscitado acabaría determinando la formalización de las enseñanzas conducentes al título oficial de Diplomado en Educación Social (Real Decreto 1420/1991, de 30 de agosto; BOE del 10 de octubre de 1991). Una titulación que diversos colectivos de educadores sociales, así como profesores e investigadores de distintos campos de conocimiento, muy significativamente desde la Pedagogía Social, en la mayoría de las Universidades venían reclamando, poniendo de relieve su perfil diferencial en relación con los estudios de Pedagogía y de Trabajo Social.

Queda constancia de estos testimonios en las palabras de Antoni Juliá $(1998,31)$, al reconocer que con la regulación de los estudios de la Diplomatura en Educación Social se produce un "hecho deseado, trabajado y hasta batallado por algunos de los colectivos profesionales", al que asocia una serie de acontecimientos de suma importancia para el devenir de los educadores sociales en nuestro país:

a) Por un lado, la regulación de la formación, con la posibilidad de creación de un Colegio Profesional que sustituya a las asociaciones profesionales y sea referencia de los derechos y deberes de los educadores en el ejercicio de su profesión, diferenciándose de los estrictamente laborales;

b) por otro, la vinculación de los estudios universitarios con la práctica profesional del educador realizada hasta la aparición de la Diplomatura;

c) finalmente, la confluencia de dos colectivos: el de los educadores diplomados y el de los educadores que desde hace tiempo venían asumiendo una práctica educativa en los diferentes servicios e instituciones, que han necesitado y creado el espacio profesional del educador social.

Con otra perspectiva, más académica, el profesor José Ortega $(1999,38)$ enjuiciaría la creación de esta titulación en términos de una oportunidad histórica, mediante la que "se establecen las condiciones que posibilitan en principio una formación más sistemática, reglada y rigurosa del educador social. Se salía al paso de una cierta confusión, se introducía una mayor clarificación conceptual y científica, se abrían caminos a la investigación, a la reglamentación y dignificación de la profesión. En cualquier caso, tanto profesionales de la educación en la práctica como estudiosos de los diferentes aspectos de la educación social, creían, y entiendo que siguen creyendo, que era y es un paso necesario y conveniente esa creación de la Diplomatura en Educación Social en el marco de la Universidad".

En esta misma dirección, el profesor Amando Vega $(1988,92)$, coincidiendo temporalmente con el debate sobre la creación y reforma de los títulos uni- 
versitarios, observaba la situación señalando como con la reforma universitaria, la Educación Social tomaba "gran fuerza en el nuevo plan de estudios", considerando que se daba un paso importante con "el reconocimiento universitario de un trabajo profesional educativo de gran trascendencia social, sobre todo si miramos hacia atrás y vemos que la intervención educativa no escolar ha estado hasta ahora marginada a todos los niveles". Martí March $(1998,56)$ señala, también en esta dirección, como "la creación de la diplomatura, a pesar de sus insuficiencias y deficiencias, no sólo supone el reconocimiento de una historia, de una realidad y de una profesión, sino también la posibilidad de construir esta profesión de una forma más viva, dinámica y permanente". A lo que añade: "si hasta la aprobación de la Diplomatura en Educación Social, este profesional ha tenido una formación plural, contradictoria y ajena a la Universidad, resulta evidente que a partir de la misma aprobación dicha formación se plantea desde un enfoque homogéneo a base de criterios de contenido, de espacios de formación, de articulación interna del mismo, de ámbitos de prácticas, de reconocimiento social y profesional con la posibilidad de la existencia de un Colegio Profesional, etc.". Uno de los últimos alegatos a la trayectoria seguida por estos estudios se plasmaba en el Libro Blanco de Grado en Pedagogía y Educación Social (Villa, 2005, 71) cuando se concluía que la demanda de sus estudios supera la oferta que realizan las instituciones universitarias, siendo "una titulación que goza de gran aceptación, que refleja perfectamente un nuevo yacimiento de empleo, expresión clara de las necesidades específicas de la sociedad actual". A lo que se añade que "la mayoría de estas Universidades ofertan a sus alumnos el acceso a un segundo ciclo en el mismo centro universitario", en una clara alusión a las titulaciones de Pedagogía y Psicopedagogía.

Sin duda, uno de los activos más importantes en el logro del reconocimiento académico de la Educación Social por parte de la comunidad universitaria, así como de aquellos que han decidido inscribir su desempeño profesional en el quehacer socio-educativo, alude directamente a su capacidad para dar respuesta a nuevas necesidades y demandas educativas, muchas de ellas emergentes en una sociedad cargada de adjetivos (postmoderna, postindustrial, de la información, del conocimiento, red, del ocio, etc.) que obligan a repensar la naturaleza y el alcance de la educación como una práctica extensible a cualquier tiempo y espacio de la vida de las personas.

Más aún, de poder hacerlo recuperando el sentido integral e integrador inherente al acto de educar, como una tarea cotidiana de amplias miras pedagógicas y sociales, en cuyo horizonte -como ya hemos argumentado en otras ocasiones (Caride, 2005)- siempre esté presente la firme voluntad de incidir en la construcción de una ciudadanía activa, plural, consciente, solidaria, inclusiva y sensible, comprometida con el logro de un mundo mucho más habitable, que agrande los derechos de los sujetos, de la convivencia y de la cohesión social. Una tarea compleja y difícil, en la que pensarse como educador o educadora social requiere de un saber (conocimientos), de un saber ser (actitudes) y de un saber hacer (destrezas) cargados de exigencias científicas, pedagógicas, 
metodológicas y éticas. Al fin y al cabo, nos referimos a un profesional que ha de acostumbrarse a los sabores agridulces que depara transitar entre la satisfacción que produce dedicarse a un quehacer profundamente socializador y humano, y la frustraciones que supone observarse limitado ante los excesos con los que se nos muestran las problemáticas sociales: en la desigualdad, en las dependencias, en la marginalidad, en el maltrato, en la discriminación, en el consumismo... Excesos para los que la educación y los/as educadores/as precisan de respuestas en los que se combinen los esfuerzos de diferentes agentes y proyectos sociales, singularmente aquellos que tienen como soporte la política y la economía. Excesos ante los que cuentan especialmente los modos de estar o de ser educador o educadora, como expresión de una postura ética y moral, ideológica, cívica... no sólo técnica o profesional. En la que importa preguntarse sobre la naturaleza de las propias acciones, sobre sus por qué y para qué en cada territorio concreto de las Administraciones o de lo que suele identificarse, no siempre con suficiente criterio, como sociedad civil.

Somos conscientes de que aludimos a exigencias y competencias que han de ser compartidas por diversos campos disciplinares, tanto en el diseño como en el desarrollo de unos Planes de Estudio (en general, todos los que conducen a la obtención de títulos en cualesquiera de las ramas de la Educación y de las Ciencias Sociales) cuya naturaleza interdisciplinar es incuestionable. De igual modo que también lo es la vocación multiprofesional y de trabajo en equipo que debe caracterizarlos. Máxime cuando su quehacer laboral converge con el de otros titulados del sistema educativo, en la Universidad y en aquellos Ciclos Formativos de Grado Medio y Superior que conducen a la obtención de títulos en familias profesionales cuyos perfiles técnicos están vinculados a los servicios sociosanitarios, socioculturales y comunitarios.

\section{DE LA FORMACIÓN A LA PROFESIÓN SIENDO “CONVERGENTES” Y "COMPETENTES"}

El Grado en Educación Social, si se toman en consideración los aspectos básicos que regulan legislativamente la creación e implantación de los títulos que participen del proceso de Bolonia, deberá compartir con todas las demás enseñanzas oficiales que conformen el catálogo de títulos existente en nuestro país, un objetivo formativo claro: propiciar la consecución por los estudiantes de una formación universitaria que aúne conocimientos generales básicos y conocimientos transversales relacionados con su formación integral, junto con los conocimientos y capacidades específicos orientados a su incorporación al ámbito laboral. Así consta en el Real Decreto 1393/2007, de 29 de octubre, por el que se establece la ordenación de las enseñanzas universitarias oficiales, al considerar que "las enseñanzas de Grado tienen como finalidad la obtención por parte del estudiante de una formación general, de una o varias disciplinas, orientada a la preparación para el ejercicio de actividades de carácter profesional" (art. 9.1). 
Para hacer compatibles estos propósitos con la Convergencia Europea de la Educación Superior se insiste en que los estudios de Grado que se propongan han de ser relevantes socialmente, tratando de conciliar una sólida formación académica con una precisa y bien definida orientación profesional, que debe reflejarse en los planes de estudio que se propongan, elaborados por las Universidades y verificados por el Consejo de Universidades de acuerdo con un procedimiento en el que la Agencia Nacional de Evaluación de la Calidad y Acreditación (ANECA) tendrá un especial protagonismo, conforme a los protocolos de verificación y acreditación previstos en el mencionado Decreto.

El proyecto de título oficial que han de presentar las Universidades para su correspondiente verificación, más allá de la descripción del título, de su justificación (argumentando el interés académico, científico o profesional del mismo), los procesos de acceso y admisión de los estudiantes, la planificación de las enseñanzas, el personal académico, los recursos materiales y servicios, los resultados previstos, el sistema de garantía de la calidad, o el calendario de implantación..., contempla en su apartado de objetivos las competencias generales y específicas que los estudiantes han de adquirir durante sus estudios. Y que, en el caso del educador o de la educadora social deben posibilitar la formación de un profesional capacitado para desarrollar profesionalmente los conocimientos científicos y los principios de acción necesarios para la comprensión, interpretación, análisis y explicación de los fundamentos teórico-prácticos de la educación en distintos espacios y tiempos sociales, en los términos en que su perfil fue definido en la ficha técnica del Grado, redactada a partir de las Jornadas celebradas en Palma de Mallorca del 22 al 23 de junio de 2006.

La Comisión Permanente de la Conferencia de Decanos y Directores de Magisterio y Educación, en sesión celebrada el pasado 6 de marzo de 2008, modificaría parcialmente este perfil identificando al educador o educadora social como un/a profesional "que realiza una intervención socioeducativa con personas y en sus contextos, con el fin de que logren su desarrollo personal y social, su integración y participación en la comunidad en diferentes ámbitos sociales", para lo que entiende que "desempeña con otros profesionales una función de intervención social y educativa en contextos sociocomunitarios". Una caracterización descriptiva insuficiente e imprecisa, que obvia dos dimensiones principales en su formulación, que si se contemplan en el perfil profesional del Grado de Pedagogía, y que deben ser corregidos: de un lado, obviar su competencia "tanto en el diseño, gestión, desarrollo y evaluación de planes, programas, proyectos y acciones educativas adaptadas y contextualizadas como en su análisis, seguimiento, asesoramiento y evaluación"; de otro, no hacer explícita las dimensiones culturales e institucionales en las que se inscribe su formación y profesionalización, tanto por motivos históricos (de los que la Animación Sociocultural o el trabajo realizado en las Administraciones Públicas, en centros y recursos institucionalmente formalizados -casas de cultura, centros cívicos, departamentos municipales de educación, servicios sociales, escuelas, etc.son un claro ejemplo) y prospectivos, como los que se ponen de relieve en la 
Resolución de 5 de junio de 2007, de la Dirección General de Trabajo, por la que se registra y publica el I Convenio colectivo marco estatal de acción e intervención social (BOE del martes 19 de junio de 2007), que entiende por acción e intervención social todas aquellas actividades o acciones "que se realizan de manera formal u organizada, que responden a necesidades sociales, que su propósito puede ser tanto prevenir, paliar o corregir procesos de exclusión social, como promover procesos de inclusión o participación social" (artículo 2.2). Dando respuesta a esta concepción, despliega un catálogo de actividades que comprende un total de 5 grandes áreas, en las que se reconoce explícitamente un quehacer educativo-social; y que, en sus enunciados principales se resumen en:

1) Área de intervención psicosocial y socioeducativa: conjunto de servicios, centros, equipos y programas dirigidos al desarrollo integral y continuo de personas, grupos y comunidades en su entorno, así como a la prevención, atención, actuación y compensación ante situaciones de desventaja y riesgo social, educativo y/o económico, desde un enfoque psicosocio-educativo.

2) Área de intervención socio-laboral: conjunto de servicios, centros, equipos y programas dirigidos a fomentar la integración social y a mejorar la calidad de vida a través de la búsqueda de espacios de empleo y ocupación que posibiliten el logro de la autonomía personal y económica, promoviendo el desarrollo armonizado de riqueza material y cultural en el ámbito local mediante actividades especificas de integración laboral, promoción de la igualdad y desarrollo local.

3) Área de intervención socio-sanitaria y asistencial: conjunto de servicios, centros, equipos y programas dirigidos a la atención tanto preventiva como asistencial hacia individuos, grupos o comunidades cuyas condiciones de salud física y o psíquica, relacionadas a su vez con determinadas necesidades sociales requieran de una intervención multidisciplinar de orden biopsicosocial con el objeto de mejorar su calidad de vida.

4) Área de intervención socio-comunitaria y sociocultural: conjunto de servicios, centros, equipos y programas dirigidos a mejorar la calidad de vida de un grupo o una comunidad con el fin de mejorar la situación social de sus componentes mediante, por un lado, procesos de estructuración y cohesión, de sensibilización ante la desigualdad y de mejora de la convivencia y por otro, a través de la articulación de procesos de participación del colectivo en su propia transformación y desarrollo humano, social y cultural fomentando la educación en valores a través de actividades culturales, lúdicas, sociales y medioambientales.

5) Área de gestión, diseño y evaluación de programas sociales: conjunto de servicios, centros, equipos y programas dirigidos a la planificación y administración de los recursos materiales tecnológicos y humanos, con 
vistas a sistematizar desde bases técnicas el desarrollo y supervisión de las labores, y la eficacia y eficiencia de las actuaciones de intervención social.

En su conjunto representa un importante hito en la concepción y, sobre todo, en el reconocimiento del quehacer profesional de quienes por formación y desempeño laboral vinculan sus tareas a procesos o prácticas de acción e intervención social, entre ellas todos aquellos profesionales de la educación que ejercen su labor en el exterior del sistema educativo. También, inevitablemente, un refrendo de la formación académica en la Formación Profesional y/o en las Universidades, que deben recibir, mediante la cual adquieren una titulación $\mathrm{y}$, consecuentemente, la posibilidad de su inserción en un mercado laboral emergente y escasamente definido en sus deberes y derechos.

En la ficha técnica de propuesta de título universitario de Grado en Educación Social, emanada de las Jornadas de Debate celebradas en Palma de Mallorca, las competencias se articulaban en tres grandes bloques, diferenciando las de carácter instrumental de las interpersonales y sistémicas, pensadas no sólo desde una lógica disciplinar sino, fundamentalmente, profesional. De ahí la insistencia en que las 16 competencias reseñadas eran el resultado de analizar, comparar, sintetizar e integrar las competencias propuestas por los educadores sociales y la Universidad, y que en gran medida eran un exponente visible de las valoraciones efectuadas por distintos colectivos (profesores, alumnos, titulados, profesionales, etc.) en el Libro Blanco elaborado por la Red de Educación y editado por la ANECA (Villa, 2005). La representación gráfica ( ${ }^{\circ}$ 2) que adjuntamos, pone de relieve la interacción existente entre ellas, así como las cinco que fueron mejor consideradas por las comunidades académicas y profesionales que fueron encuestadas. 


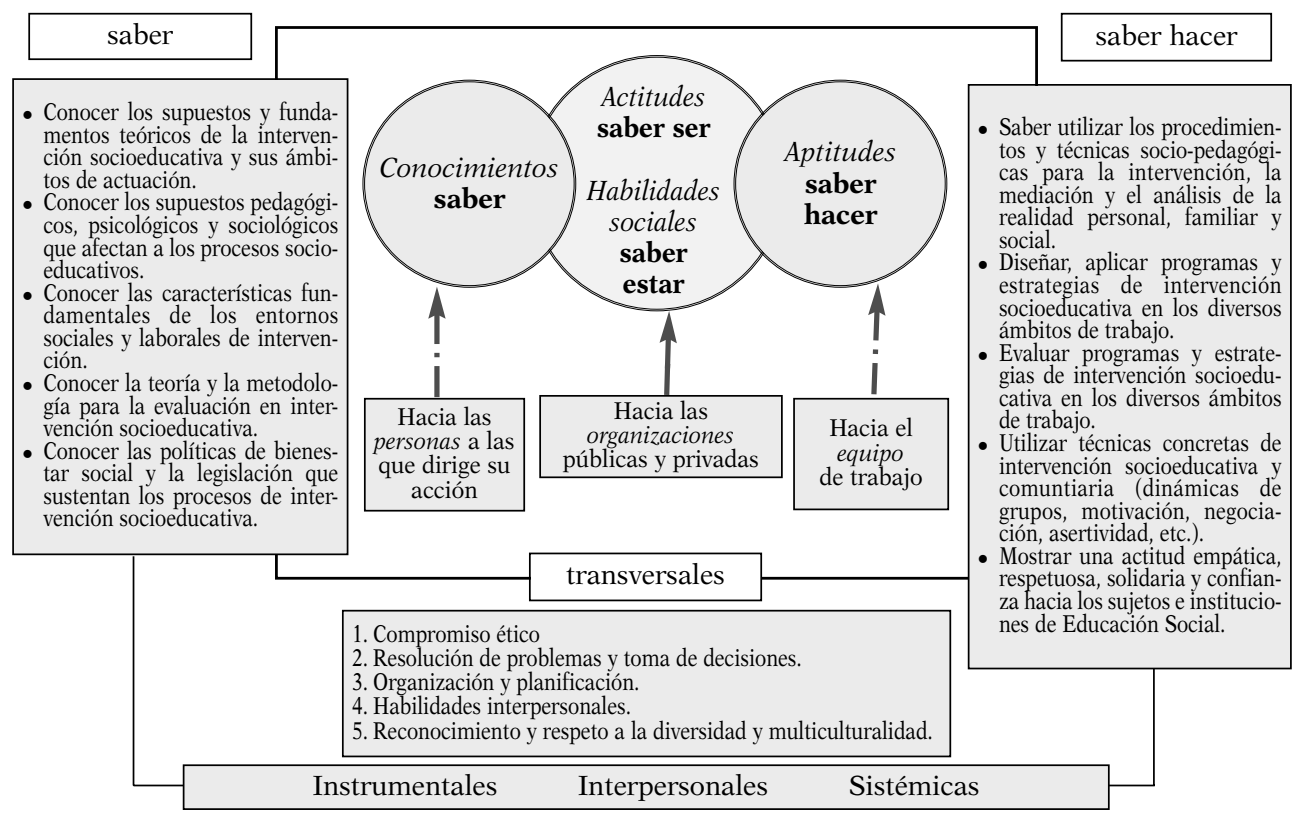

Gráfica $n^{\circ} 2$; Competencias relacionales (transversales y específicas) de los profesionales de la Educación Social

Fuente:

Romans, M. (2000): Formación continua de los profesionales en Educación Social. En Romans, M.; Petrus, A. y Trilla, J.: De profesión educador(a) social. Paidós, Barcelona, 172.

ANECA (2005): Libro Blanco Título de Grado en Pedagogía y Educación Social, vol. 1. ANECA,

Madrid, 299-302.

Adaptación propia.

Para la Asociación Estatal de Educación Social (ASEDES), las competencias deberían tener una orientación claramente profesionalizadora, en función del ámbito y responsabilidad profesional y laboral que le corresponde desempeñar al educador o a la educadora social, concretando su propuesta en seis áreas principales:

- Transmisión, desarrollo y promoción de la cultura.

- Generación de redes sociales, contextos, procesos y recursos educativos y sociales.

- Mediación social, cultural y educativa (compartida con otros profesionales).

- Conocimiento, análisis e investigación de los contextos sociales y educativos.

- Diseño, implementación y evaluación de programas y proyectos educativos.

- Gestión, dirección, coordinación y organización de instituciones y recursos educativos. 
Como ya hemos indicado, la Comisión Permanente de la Conferencia de Decanos y Directores de Magisterio y Educación, ha reformulado la estructura inicial de competencias específicas propuestas, tanto para el Grado de Pedagogía como para el de Educación Social, agrupándolas en siete grandes bloques, que van desde el conocimiento, comprensión y análisis crítico hasta la mejora permanente de la profesión, investigación sobre la propia práctica e intercambio profesional.

Por lo que se refiere a la estructura curricular el Libro Blanco editado por la ANECA concretaba una propuesta en la que figuran 144 créditos ECTS, con los descriptores y las competencias específicas, así como la carga horaria que en su momento- se valoraron como esenciales o complementarias para cada uno de los bloques de contenido troncal, a partir del estudio realizado por la Red de Educación. Y que, a la espera del debate que se produzca en las Universidades y en los ámbitos de decisión que han participado activamente en las propuestas conocidas, se resumen en los siguientes epígrafes:

- Bases conceptuales y contextuales de la educación.

- Intervención socioeducativa en contextos no formales e informales.

- Metodologías de la investigación en intervención socioeducativa y tecnologías educativas.

- Diseño, gestión y evaluación de programas de intervención socioeducativa.

- Técnicas, medios y recursos en la intervención socioeducativa.

- Prácticum.

En los términos en los que está actualmente planteado el diseño de los títulos, son contenidos que deberán añadirse a la formación proporcionada por las materias básicas, posibilitando la cualificación teórico-práctica de un educador o educadora social cuya identidad académica y profesional esté vertebrada por tres líneas de acción que subrayen aprendizajes que posibiliten:

- Capacidades, competencias, habilidades y conocimientos polivalentes diversos;

- interpretar y proyectar en toda su complejidad y diversidad la acciónintervención socioeducativa;

- con una mentalidad abierta a la pluralidad de los saberes y metodologías, de clara vocación praxiológica.

Que esto sea así nos hace pensar en un profesional de la Educación Social crítico y reflexivo, comprometido con las realidades territoriales y humanas en las que desarrolla sus prácticas pedagógicas y sociales, como agente inductor y/o mediador de procesos de cambio y transformación social, en los que los Derechos Humanos, el bienestar de las personas y su calidad de vida han de ser referentes principales para el logro de una sociedad más inclusiva, equitativa y justa. De ahí que no se trate tan sólo de hacer converger a los educadores y a la 
Educación Social con los parámetros académicos-profesionales que prevé el EEES, sino también de aquellos que ponen de relieve la necesidad de la figura profesional del educador en las políticas sociales y educativas europeas, tal y como analizan Scarpa y Corrente $(2007,66)$ al recordar que "el interés europeo por esta figura emerge en el instante en que la UE se interesa por el ser humano en su complejidad y se plantea el problema de la calidad de vida de las sociedades". De modo que, siendo inevitable admitir que es una profesión cercada por ambigüedades y dificultades a la hora de establecer un perfil común y una homologación compartida de competencias, también lo sea que Europa "tiene la necesidad de profesionales formados, competentes, reconocidos que puedan hacer frente a los retos y las prioridades sociales, de manera que puedan distinguirse de los no cualificados y de los voluntarios. Profesionales formados y competentes en los campos del conocimiento, saber-ser y saber hacer, y saber dónde y cómo intervenir", concluyen Scarpa y Corrente $(2007,73)$, asumiendo que tales competencias si bien deben adquirirse en la formación inicial, han de continuar construyéndose en la formación permanente durante toda la trayectoria de la carrera profesional.

$\mathrm{Ni}$ antes ni después ha sido o será un trayecto fácil. Ni en los momentos iniciales que, hace poco más de veinte años, depararon la creación de la Diplomatura en Educación Social en las Universidades españolas. Ni ahora, cuando ilusionadamente se aspira a acomodar plenamente sus realidades formativas y profesionales en el marco de la convergencia europea. Al respecto no podemos dejar de coincidir con el profesor Martí March (2007, 41-42) cuando valora que hay dos hechos importantes que condicionan el proceso de convergencia europea: de un lado, "la diversidad de titulaciones europeas en relación a la Educación Social, tanto en el ámbito de la Universidad como de la educación superior", poniendo de manifiesto no sólo la pluralidad de concepciones existentes en relación a las funciones o ámbitos en los que interviene la Educación Social, sino también "la falta de un criterio unificador de cuál debe ser la respuesta universitaria, a nivel de titulación a la misma". De otro, "la falta de una política social común en la Unión Europea en dos ámbitos clave para el establecimiento de una titulación europea de Educación Social: la educación y los servicios sociales".

No obstante, y aún admitiendo las complicaciones que estas circunstancias podrán generar, tenemos la firme convicción de que la Educación Social nunca ha estado en mejores condiciones para afrontarlas, con soluciones tangibles académica y profesionalmente. Porque más allá de las dificultades que comporta resolver acertadamente las problemáticas a las que ha de darse respuesta, también constituyen un desafío especialmente sugerente, en lo pedagógico y en lo social, a favor de una sociedad educadora y de la condición ciudadana, como no hace mucho tuvimos la oportunidad de argumentar (Caride, 2007) haciéndonos eco del sentir unánime de quienes, desde hace años, hemos vinculado nuestro quehacer colectivo a la Sociedad Iberoamericana de Pedagogía Social. 


\section{REFERENCIAS BIBLIOGRÁFICAS}

Benítez, J. L. y otros (2006). La Universidad ante el reto del Espacio Europeo de Educación Superior: Investigaciones recientes. Madrid: Editorial Eos.

Caride, J. A. (2005). Las fronteras de la Pedagogía Social: perspectivas científica e histórica. Barcelona: Gedisa.

Caride, J. A. (2007). La Pedagogía Social ante el proceso de convergencia europea de la Educación Superior. Pedagogía Social: Revista Interuniversitaria, 14 (3 época), 11-31.

EURYDICE (2007). Focus on the Structure of Higher Education in Europe 2006/07. National Trends in the Bologna Process. Bruselas: EURYDICE-Comisión Europea.

Fontaine, P. (2003). Doce lecciones sobre Europa. Luxemburgo: Oficina de Publicaciones Oficiales de las Comunidades Europeas.

Gallifa, J. (2005). El Espacio Europeo de Educación Superior y la Educación Social. Educación Social: Revista de Intervención socioeducativa, 29, 10-14.

Juliá, A. (1998). El educador social: una figura profesional surgida de diversas prácticas e identidades profesionales. FEAPES: Actas del I Congreso Estatal del Educador Social: presente y futuro en la Educación Social. Barcelona: FEAPESBiblária, 31-45.

Lizasoaín, L. (2005): La reforma de las titulaciones y la Convergencia con el Espacio Europeo de Educación Superior. En Ruiz Berrio, J. (ed.). Pedagogía y Educación ante el siglo XXI. Departamento de Teoría e Historia de la Educación de la Universidad Complutense, Madrid, 715-730.

Maiztegui, C. y Santibáñez, R. (coord.) (2002). El futuro del educador: perfiles profesionales y adaptación de los pedagogos y educadores sociales a una sociedad en cambio. Bilbao, Universidad de Deusto.

March, M. (1998). El educador social: una figura profesional surgida de diversas prácticas e identidades profesionales. FEAPES: Actas del I Congreso Estatal del Educador Social: presente y futuro en la Educación Social. Barcelona: FEAPESBiblária, 49-67.
March, M. (2007). La Educación Social en el marco de la construcción del Espacio Europeo de Educación Superior. Pedagogía Social: Revista Interuniversitaria,

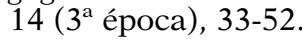

MEC (2007). Implantación del nuevo Sistema Educativo. MEC (documento interno).

En: http://www.mec.es/educa/sistemaeducativo/loe/files/aplicacion-loe.pdf

Michavila, F. y Zamorano, S. (2007). Reflexiones sobre los cambios metodológicos anunciados en la Educación Superior en España. Educación y Futuro, 16, 31-46.

Muñoz Sedano, A. (ed.) (1994). El educador social: profesión y formación universitaria. Madrid: Popular.

Ortega, J. (1999). Educación Social Especializada, concepto y profesión, en Ortega, J. (coord.). Educación Social Especializada. Barcelona: Ariel, 13-41.

Pérez Serrano, G. (2003). Pedagogía SocialEducación Social: construcción científica e intervención práctica. Madrid: Narcea.

Romans, M. (2000). Formación continua de los profesionales en Educación Social, en Romans, M., Petrus, A. y Trilla, J. De profesión educador(a) social. Barcelona: Paidós, 149-277.

Ruiz, C. (coord.) (2003). Educación Social: viejos usos y nuevos retos. Valencia: Universitat de Valencia.

Sáez, J. (2005). La profesionalización de los educadores sociales: construcción de un modelo teórico para su estudio. Revista de Educación, 336, 129-139.

Sáez, J. y García Molina, J. (2006). Pedagogía Social: pensar la Educación Social como profesión. Madrid: Alianza.

Scarpa, P. y Corrente, M. (2007). La dimensión europea del Educador/a Social. Pedagogía Social: Revista Interuniversitaria, 14 ( $3^{\mathrm{a}}$ época), 63-74.

Vega, A. (1988). La formación de profesionales relacionados con la Educación Social. Revista Interuniversitaria de Formación del Profesorado, 3, 83-93.

Villa, A. (coord.) (2005). Libro Blanco Título de Grado en Pedagogía y Educación Social. Madrid: ANECA (2 vols.). 


\section{PALABRAS CLAVE}

Educación Social, Espacio Europeo de Educación Superior, Universidad, competencias, perfil profesional, educadores sociales.

\section{KEY WORDS}

Social Education, European Higher Education Area, University, Competences, Professional Profile, Social Educators.

\section{PERFIL ACADÉMICO DEL AUTOR}

José Antonio Caride Gómez es Doctor en Filosofía y Ciencias de la Educación (Pedagogía). Catedrático de Pedagogía Social en el Departamento de Teoría de la Educación, Historia de la Educación y Pedagogía Social de la Facultad de Ciencias de la Educación de la Universidad de Santiago de Compostela, en la que dirige el Grupo de Investigación "Pedagogía Social y Educación Ambiental" (SEPA-interea). Desde el año 2002 preside la Sociedad Iberoamericana de Pedagogía Social, de la que fue miembro fundador.

Dirección del autor: Dpto. de Teoría de la Educación, $\mathrm{H}^{\mathrm{a}}$. de la Educación y Pedagogía Social $F^{a}$. de Ciencias de la Educación, campus sur Universidad de Santiago de Compostela 15782 - Santiago de Compostela (España) E-mail: hecaride@usc.es

Fecha recepción del artículo: 31. marzo. 2008

Fecha aceptación del artículo: 15. abril. 2008 